\title{
DENGUE NO MUNICÍPIO DE BARUERI, SÃO PAULO - PERFIL EPIDEMIOLÓGICO ENTRE 2009-2013
}

\author{
DENGUE IN BARUERI, SÃO PAULO - EPIDEMIOLOGICAL PROFILE BETWEEN \\ 2009-2013
}

\author{
E. M. N. PAULA ${ }^{1}$, C. A. CRUZ ${ }^{2}$, C. S. L. NOGUEIRA ${ }^{2 *}$, R. B. MEIRELLES-BARTOLI ${ }^{1}$, \\ A. A. B. CARVALHO ${ }^{2}$
}

\section{RESUMO}

Barueri é um município do Estado de São Paulo que, assim como tantos outros, vem enfrentando dificuldades com crescente número de casos de dengue. Essa doença é causada por um Flavivirus, transmitido pelo mosquito Aedes aegypti; e tem apresentação clínica variando de uma forma branda a um quadro grave, podendo evoluir ao óbito. Objetivou-se realizar uma avaliação epidêmica sobre essa doença em Barueri, SP, de 2009 a 2013, avaliando casos notificados, retirados do Centro de Vigilância Epidemiológica. Buscou-se também a distribuição dos casos de acordo com ano, bem como analisar o nível endêmico entre os anos de 2009 e 2012, comparados com o ano de 2013. O critério estatístico utilizado foi o Método dos Quartis juntamente com método do nível endêmico. Entre 2009 e 2013, 394 casos de dengue foram notificados em Barueri. Destes, 186 (47,72\%) ocorreram em 2013. Em todos os anos analisados, o primeiro semestre apresentou maior representatividade em relação ao segundo. As notificações começam a aumentar a partir do mês de janeiro, tendo seu pico em março e a redução se dá nos meses seguintes, porém sempre em situação epidêmica. Portanto, de acordo com a série histórica da doença, no ano de 2013 houve sim uma epidemia de dengue nesse município. Podem-se considerar algumas possibilidades de explicações, por meio da análise dos dados encontrados e da interpretação destes, gerando hipóteses. De forma geral, há necessidade de melhoria na prevenção e controle da doença, além de estudos epidemiológicos.

PALAVRAS-CHAVE: DENGUE. SAÚDE. VIGILÂNCIA EPIDEMIOLÓGICA. FLAVIVIRUS.

ÁREA TEMÁTICA: Saúde Pública

\footnotetext{
${ }^{1}$ Universidade Federal de Goiás (UFG), Regional Jataí, Unidade Jatobá, Laboratório de Sanidade Animal ${ }^{2}$ Faculdade de Ciências Agrárias e Veterinárias da Universidade Estadual Paulista (UNESP) - Câmpus de Jaboticabal

* carolnogueira.vet@gmail.com
} 